\title{
RATIONAL ERROR CORRECTION
}

\author{
P. A. Tinsley* \\ Division of Research and Statistics \\ Federal Reserve Board \\ Washington DC 20551 \\ ptinsley@frb.gov
}

version: July 1998

\begin{abstract}
Under general conditions, linear decision rules of agents with rational expectations are equivalent to restricted error corrections. However, empirical rejections of rational expectation restrictions are the rule, rather than the exception, in macroeconomics. Rejections often are conditioned on the assumption that agents aim to smooth only the levels of actions or are subject to geometric random delays. Generalizations of dynamic frictions on agent activities are suggested that yield closed-form, higher-order decision rules with improved statistical fits and infrequent rejections of rational expectations restrictions. Properties of these generalized "rational" error corrections are illustrated for producer pricing in maufacturing industries.
\end{abstract}

Keywords: Companion systems, error correction, producer pricing, rational expectations

JEL classifications: C5, E3

*I am indebted for comments on an earlier version of this paper by colleagues and others, especially F. Diebold, S. Johansen, and S. Kozicki. Views presented are those of the author and do not necessarily represent those of the Federal Reserve Board. 
Intertemporal decision rules are indispensable in rational agent interpretations of macroeconomic behavior where a distinction is drawn between agent perceptions, summarized by agent forecasts of market events, and agent responses, subjected to dynamic constraints or "frictions." In theoretical macroeconomic models since Lucas (1976), rational expectations have become the benchmark standard for representing the unobserved forecasts of agents.

Unfortunately, the record for empirical implementation of rational expectations models remains dismal. A survey of existent journal publications by Ericsson and Irons (1995) summarizes an extensive accumulation of empirical evidence against rational expectations, including frequent rejections of rational expectations overidentifying restrictions. A review of policy simulation models used by central banks and international agencies, such as documented in Bryant et al. (1993), indicates that many key rational expectations specifications are either imposed or fit by rough empirical calibrations.

Macroeconomists have adopted a variety of responses to the absence of strong empirical support for rational expectations. One is to maintain the rational expectations hypothesis, while aiming to interpret a more limited subset of empirical regularities as discussed by Kydland and Prescott (1991). Another approach is to view rational expectations as a limiting case of complete information in a more general treatment of the information processing abilities of agents, such as the "bounded rationality" models of learning reviewed in Sargent (1993). Closely related is the position that rational expectations are more likely to prevail at low frequencies, a view compatible with tests of long-run theoretical restrictions in cointegrating relationships, as discussed by Watson (1994). Others reject the hypothesis of model-based rational expectations, such as the use in Ericsson and Hendry (1991) of rule-of-thumb extrapolations.

This paper examines an alternative explanation for the poor empirical properties of rational expectations models. Because most rational expectations restrictions are inherently dynamic due to the forecasting requirements of constraints on dynamic adjustment, a plausible source of difficulty could be the sharp friction priors typically imposed on agent responses. The standard dynamic specification in rational expectations models utilizes geometric lead response schedules to anticipated future events and geometric lag responses to recent "news." Because this two-sided geometric response schedule is not a clear implication of economic theory, a generalized polynomial frictions specification is explored in this paper. Suggested interpretations of generalized frictions range from costs of adjusting weighted averages of current and lagged actions to convolutions of geometric random delay distributions of agent responses.

For difference-stationary variables, the decision rules based on generalized frictions are shown to be isomorphic to a class of "rational" error correction models." The parameters of the

\footnotetext{
${ }^{1}$ Discussion in this paper is aimed primarily at decision rules for difference-stationary variables, a specification that is not rejected by standard tests of the integration order of most macroeconomic aggregates in postwar samples.
} 
decision rules are subject to tight cross-coefficient restrictions due to polynomial frictions and cross-equation restrictions due to the assumption of rational expectations. A closed-form solution that incorporates these restrictions is derived using two companion matrix systems, one a lead system for the forward planning required by polynomial frictions and the other a lag system associated with the agents' forecast model. ${ }^{2}$

Rational error corrections under polynomial frictions inherit many desirable properties of atheoretic reduced-form time-series models, including serially independent equation residuals and small standard errors relative to many theory-based alternatives. However, whereas conventional error corrections and VARs have been criticized for in-sample overfitting attributable to large numbers of estimated parameters, rational error corrections are subject to many overidentifying restrictions which substantially reduce the number of free parameters.

To provide concrete illustrations of the consequences of restrictive priors on adjustment costs, linear decision rules associated with alternative specifications of frictions are estimated for producer pricing in several manufacturing industries. The basic specification is based on the assumptions of difference-stationary producer prices and stationary price markups over costs of production, assumptions that are not rejected for postwar U.S. producer prices. ${ }^{3}$

A difficulty with interpreting many reported rejections of rational expectations overidentifying restrictions is that the rejections could be due also to misspecified models. An advantage of the side-by-side comparisons reported in this paper is that several empirical problems, including rejections of rational expectations restrictions, are unambiguously linked to the use of second-order Euler equations rather than higher-order Euler equations.

The paper is organized as follows. Section I summarizes dynamic properties of the restricted error correction that is implied by the standard decision rule with geometric response schedules. Section II derives the error correction format of rational decision rules implied by a generalized polynomial description of frictions. Several interpretations of polynomial frictions are suggested. Section III presents empirical estimates of decision rules for industry pricing, comparing the geometric responses of the standard decision rule with the responses of higher-order decision rules. A tractable method of two-stage maximum likelihood estimation of rational error corrections

\footnotetext{
${ }^{2}$ Although this paper develops a general framework for formulating higher-order error correction decision rules, there are several precedents for recasting decision rules as restricted error corrections or applying higher-order linear decision rules to macroeconomic aggregates. Nickell (1985) appears to be the first paper to explore similarities between second-order decision rules and error correction models. Generally, fourth-order decision rules have been confined to empirical inventory models, such as Blanchard (1983), Hall, Henry, and Wren-Lewis (1986), Callen, Hall, and Henry (1990), and Cuthbertson and Gasparro (1993). Exceptions are the applications of fourth-order decision rules to employment in the coal industry by Pesaran (1991) and to the price of manufactured goods in Price (1992).

${ }^{3}$ State-independent frictions in pricing would not be expected to hold over all possible states, such as episodes of extreme hyperinflation. Nevertheless, linear time series models appear to be a useful way to analyze sticky pricing in periods of moderate inflation, vid. Sims (1992) and Christiano, Eichenbaum, and Evans (1994).
} 
is derived in the Appendix, including corrections required for the sampling errors of the second stage. Section IV concludes.

\section{Rational Error Correction under Geometric Frictions}

Just as one-sided polynomials in the lag operator are characteristic of atheoretic, linear time series models, two-sided polynomials in the lead and lag operators are a defining characteristic of linear models of rational behavior. The principal vehicle of analysis in this paper is the dynamic first-order condition linking a decision variable, $y_{t}$, to its equilibrium objective, $y_{t}^{*}$,

$$
E_{t}\left\{A(L) A(B F) y_{t}-A(1) A(B) y_{t}^{*}\right\}=0
$$

where $E_{t}\{$.$\} denotes expectations based on information at the end of t-1 ; A(L)$ is a backwards scalar polynomial in the lag operator, $L^{j} x_{t}=x_{t-j}, ; A(B F)$ is a forward scalar polynomial in the lead operator, $F^{j} x_{t}=x_{t+k}$, and $B$ is a discount factor, $0<B<1$.

In contrast to conventional backwards-looking time series models of the relationship between $y_{t}$ and $y_{t}^{*}$, a notable feature of equation (1) is that the expectation of the current decision variable,

$$
\begin{aligned}
E_{t}\left\{y_{t}\right\} & =E_{t}\left\{A(1) A(B) A(L)^{-1} A(B F)^{-1} y_{t}^{*}\right\} \\
& =E_{t}\left\{\sum_{i=-\infty}^{\infty} w_{i} y_{t+i}^{*}\right\}
\end{aligned}
$$

is a two-sided moving average of past and expected future values of the desired equilibrium, $y^{*}$. The agent response schedule, $w_{i}$, determines the relative importance of past and future, where $\sum_{i=-\infty}^{\infty} w_{i}=1$. Many models used in macroeconomics assume these relative importance weights are adequately represented by two-sided geometric response schedules.

In the case of linear decision rules, there are two prominent rationalizations of geometric response schedules. One is that changes in the level of the decision variable are subject to quadratic adjustment costs, and this strictly convex friction induces geometric adjustments of the decision variable toward its equilibrium. The second interpretation is that each agent is subjected to a geometric distribution of random delays in adjustment, so that the level selected for a decision variable in a given period is a weighted average of desired target settings over the expected interval between allowable resets. As noted by Rotemberg (1996), the assumption of a geometric random delay distribution leads to aggregate behavior that is observationally equivalent to that generated by the assumption of quadratic costs on adjusting the level of the aggregate decision variable.

Under either interpretation, the required Euler equation is second-order, implying that the 
polynomial components of equation (1) are first-order polynomials, $A(L)=(1-\lambda L)$ and $A(B F)=(1-\lambda B F)$, where $0<\lambda<1$. As in Tinsley (1970), the optimal decision rule that satisfies the Euler equation and the relevant endpoint (initial and transversality) conditions implies partial adjustment of the decision variable to a discounted weighted average of expected forward positions of the desired equilibrium. ${ }^{4}$ This decision rule solution is obtained by multiplying the Euler equation (1) by the inverse of the lead polynomial, $A(B F)^{-1}$,

$$
E_{t}\left\{\Delta y_{t}\right\}=-A(1)\left(y_{t-1}-y_{t-1}^{*}\right)+E_{t}\left\{A(1) \sum_{i=0}^{\infty}(\lambda B)^{i} \Delta y_{t+i}^{*}\right\}
$$

where $\lambda B$ is the geometric discount factor over the infinite planning horizon.

To complete the derivation of the conventional decision rule, the data generating process of the forcing term, $y_{t}^{*}$, must be provided. In linear decision rules, the decision variable, $y$, is cointegrated with the conditional equilibrium target, $y^{*}$, which is defined by a linear function of $q$ variables. ${ }^{5}$

$$
y_{t}^{*}=\sum_{j=1}^{q} b_{j} x_{j, t} .
$$

Agent forecasts of the target, $y_{t+i}^{*}$, are assumed in this paper to be generated by $p$-order VARs in the $q$ arguments, $x_{t}^{\prime}=\left[x_{1, t}, \ldots, x_{q, t}\right]$. Thus, the effective information set of agents is obtained by stacking $p$ lags of the regressors, into a single vector, $z_{t-1}^{\prime}=\left[x_{t-1}^{\prime}, \ldots, x_{t-p}^{\prime}\right]$. The companion form of the agent VAR forecast model is denoted by $E_{t}\left\{z_{t}\right\}=H z_{t-1} \cdot{ }^{6}$ Consequently, agent forecasts of the forcing term of the Euler equation are generated by

$$
E_{t}\left\{y_{t+i}^{*}\right\}=\iota_{*}^{\prime} H^{i+1} z_{t-1},
$$

where the $p q \times 1$ selector vector, $\iota_{*}$, contains the coefficients of the cointegrating relationship, (4), that defines the equilibrium objective.

Substituting forecasts of the forcing term from (5) into the decision rule (3) yields

$$
\begin{aligned}
E_{t}\left\{\Delta y_{t}\right\} & =-A(1)\left(y_{t-1}-y_{t-1}^{*}\right)+A(1) \iota_{*}^{\prime} \sum_{i=0}^{\infty}(\lambda B H)^{i}\left[H-I_{n}\right] z_{t-1}, \\
& =-A(1)\left(y_{t-1}-y_{t-1}^{*}\right)+h_{*}^{\prime} z_{t-1} .
\end{aligned}
$$

\footnotetext{
${ }^{4}$ Historical references and discussion of issues in formulating linear decision rules with dynamic forcing terms are found in Tinsley $(1970,1971)$.

${ }^{5}$ As needed, the $q$ variables include deterministic trend, intercept, and seasonal dummy series. The concept of a dynamic, frictionless equilibrium is discussed by Frisch (1936).

${ }^{6}$ Companion forms for a variety of linear forecasting models are illustrated in Swamy and Tinsley (1980).
} 
As shown in the first line of (6), given the matrix of the forecast model coefficients, $H$, and the discount factor, $B$, a single friction parameter determines a geometric pattern of rational dynamic responses, $\lambda=1-A(1)$. The second line of (6) indicates that the weighted sum of expected forward changes in the forcing term, $E_{t}\left\{\Delta y_{t+i}^{*}\right\}$, can be reduced to the inner product of a restricted coefficient vector times the industry information set

$$
h_{*}=(1-\lambda)\left[H^{\prime}-I_{n}\right]\left[I_{n}-\lambda B H^{\prime}\right]^{-1} \iota_{*},
$$

where equation (7) provides a transparent summary of rational expectations overidentifying restrictions on the coefficient vector of the agent information vector, $z_{t-1}$.

Thus, there are two principal differences between the dynamic format of the "rational" error correction in equation (6) and the format of a conventional error correction with $p$ lags of each regressor. First, only one lag of the decision variable is specified by the second-order decision rule in equation (6), whereas up to $p-1$ additional lags of the first-difference of the decision variable may appear in a conventional error correction. Second, as indicated in equation (7), the coefficient vector, $h_{*}$, is completely determined by cross-coefficient restrictions due to the friction parameter in the error correction coefficient, $\lambda$, and cross-equation restrictions due to the forecast model coefficients, $H$. By contrast, the coefficients of the information vector in a conventional error correction are unrestricted. ${ }^{7}$

Residual independence and rational expectations overidentifying restrictions are frequently rejected in macroeconomic studies of rational behavior. ${ }^{8}$ One interpretation of the often disappointing empirical performances of conventional two-root decision rules, including rejections of rational expectation restrictions, is simply that expectations of actual agents may not be formed under conditions required for rational expectations, such as symmetric access to full system information by all agents. However, the limited dynamic specifications illustrated in equation (6) suggest another contributing factor-the arbitrary prior that agents responses are adequately captured by two-sided geometric response schedules. The next section explores the dynamic formats of higher-order Euler equations and rational error corrections associated with a polynomial generalization of agent response schedules.

\footnotetext{
${ }^{7}$ In conventional error corrections, an unrestricted coefficient vector is applied to the first-difference of the information vector.

${ }^{8}$ Examples of studies that report rejections of restrictions imposed by rational expectations include Sargent (1978), Meese (1980), Rotemberg (1982), Pindyck and Rotemberg (1983), and Shapiro (1986). Significant residual autocorrelations are indicated for rational expectations decision rules in Epstein and Denny (1983), Abel and Blanchard (1986), and Muscatelli (1989). See also the extensive rational expectations literature review in Ericsson and Irons (1995).
} 


\section{Rational Error Corrections under Polynomial Frictions}

The standard second-order Euler equation provides a two-sided geometric description of agent responses to anticipated and past events. The geometric schedules are determined by the roots of the first-order component polynomials, $\mathrm{A}(\mathrm{L})$ and $\mathrm{A}(\mathrm{BF})$. This section discusses decision rules associated with higher-order Euler equations, where the degree of the component polynomials is increased to $m>1$. These $m$-order polynomials are obtained by relaxing the modeling prior that agents aim to smooth only the levels of decision variables or, equivalently, that stochastic delays of decision variable adjustment are generated only by geometric distributions. The first subsection derives the closed form of rational error correction decision rules associated with higher-order Euler equations. The second subsection briefly reviews some categories of polynomial frictions on agent actions that are consistent with $2 m$-order Euler equations.

\section{II.1 Solving for Rational Error Correction Decision Rules with Higher-Order Euler Equations}

As demonstrated later in this section, the Euler equation under polynomial frictions is the same as that initially shown in equation (1), except the factor polynomials are now $m$-order polynomials, $A(L)=1+a_{1} L+\ldots+a_{m} L^{m}$, instead of first-order polynomials.

To obtain the decision rule in the case of $2 m$-order Euler equations, multiply by the inverse of the lead polynomial, $A(B F)^{-1}$, to give

$$
\begin{aligned}
E_{t}\left\{A(L) y_{t}\right\} & =E_{t}\left\{A(B F)^{-1} A(B) A(1) y_{t}^{*}\right\} \\
& \equiv E_{t}\left\{f_{t}\right\}
\end{aligned}
$$

The analytical solution for the forcing term of this equation, $f_{t}$, is obtained by introducing a second companion system that describes the forward motion of the $(m-1) \times 1$ lead vector, $g_{t} \equiv E_{t}\left\{\left[f_{t+m-1}, \ldots, f_{t}\right]^{\prime}\right\}$, over the planning horizon,

$$
\begin{aligned}
g_{t} & =E_{t}\left\{G g_{t+1}+A(B) A(1) \iota_{m} y_{t}^{*}\right\} \\
& =E_{t}\left\{A(B) A(1) \sum_{i=0}^{\infty} G^{i} \iota_{m} y_{t+i}^{*}\right\}
\end{aligned}
$$

where the $m \times 1$ selector vector, $\iota_{m}$, has a one in the $m$ th element and zeroes elsewhere; $E_{t}\left\{f_{t}\right\} \equiv$ $\iota_{m}^{\prime} g_{t}$; and $G$ is the $m \times m$ bottom row companion matrix of the lead polynomial, $A(B F)$,

$$
G=\left[\begin{array}{cccc}
0 & & I_{m-1} \\
-a_{m} B^{m} & -a_{m-1} B^{m-1} & \ldots & -a_{1} B
\end{array}\right]
$$


Substituting the solution of the forcing term, $f_{t}$, from equation (9) into (8) yields the generalized $2 m$-order decision rule,

$$
\begin{aligned}
E_{t}\left\{\Delta y_{t}\right\} & =-A(1) y_{t-1}+A^{*}(L) \Delta y_{t-1}+E_{t}\left\{A(B) A(1) \iota_{m}^{\prime} \sum_{i=0}^{\infty} G^{i} \iota_{m} y_{t+i}^{*}\right\} \\
& =-A(1)\left(y_{t-1}-y_{t-1}^{*}\right)+A^{*}(L) \Delta y_{t-1}+E_{t}\left\{A(B) A(1) \iota_{m}^{\prime} \sum_{i=0}^{\infty}\left[I_{m}-G\right]^{-1} G^{i} \iota_{m} \Delta y_{t+i}^{*}\right\}
\end{aligned}
$$

In the first line of (10), the lag polynomial is partitioned into a level and difference format, $A(L) \equiv$ $A(1) L+\left(1-A^{*}(L) L\right)(1-L)$, where $A^{*}($.$) is an (m-1)-order polynomial whose coefficients$ are moving sums of the coefficients of $\mathrm{A}($.$) , as shown in the Appendix. The second line of (10)$ partitions the forward path of the target into an initial level and forward differences, and uses the identity, $\iota_{m}^{\prime}\left[I_{m}-G\right]^{-1} \iota_{m} \equiv A(B)^{-1}$, to isolate the error correction "gap," $y_{t-1}-y_{t-1}^{*}$.

The final step in deriving the decision rule under polynomial frictions is to eliminate forecasts of the equilibrium path, $E_{t}\left\{y_{t+i}^{*}\right\}$, using the companion form of the forecast model. Substituting forecasts of forward changes $E_{t}\left\{\Delta y_{t+i}^{*}\right\}$, from (5) into (10) provides the closed form solution of the generalized rational error correction decision rule ${ }^{9}$

$$
\begin{aligned}
E_{t}\left\{\Delta y_{t}\right\} & =-A(1)\left(y_{t-1}-y_{t-1}^{*}\right)+A^{*}(L) \Delta y_{t-1}+A(B) A(1) \iota_{m}^{\prime} \sum_{i=0}^{\infty}\left[I_{m}-G\right]^{-1} G^{i} \iota_{m} \iota_{*}^{\prime} H^{i}\left[H-I_{p q}\right] z_{t-1}, \\
& =-A(1)\left(y_{t-1}-y_{t-1}^{*}\right)+A^{*}(L) \Delta y_{t-1}+h_{*}^{\prime} z_{t-1} .
\end{aligned}
$$

There are two major differences in the dynamic formats of the polynomial frictions version of rational error correction in equation (11) and the conventional geometric frictions variant shown earlier in (6). First, use of the $m$-order component polynomial, $A(L)$, introduces $m-1$ lags of the dependent variable, $A^{*}(L) \Delta y_{t-1}$ to accompany the single lag of the decision variable in the error correction term. ${ }^{10}$ Second, in contrast to the single forward discount factor, $\lambda B$, employed by the decision rule under geometric frictions in (3), forecasts of anticipated changes in the equilibrium path are now discounted by the $m$ eigenvalues embedded in the lead companion matrix, $G$.

Just as the rational expectations restrictions were summarized by a coefficient vector under the geometric frictions prior, coefficient restrictions of the generalized rational error correction also can be compactly stated. As indicated in the last line of (11), the sum of the forward-looking terms is again equivalent to the inner product of a weighting vector, $h_{*}$, and the information vector, $z_{t-1}$,

\footnotetext{
${ }^{9}$ The direct solution format using companion forms may be compared with alternative solution methods for linear decision rules ranging from partial fractions expansions of the characteristic roots in Hansen and Sargent (1980) to Schur decompositions in Anderson and Moore (1985) and Anderson, Hansen, McGrattan, and Sargent (1996).

${ }^{10}$ Note that $m$ will often be much smaller that the number of lags of the dependent variable in a conventional error correction, $m<q$.
} 
Two types of restrictions are imposed on the coefficient vector, $h_{*}$, under polynomial frictions: the cross-coefficient restrictions imposed by the component polynomials of the Euler equation, as summarized by the forward companion coefficient matrix $G$; and the cross-equation restrictions imposed by the agents' forecast model, summarized by the lag companion coefficient matrix $H$. To reveal these restrictions, successive column stacks are applied to simplify the solution for the coefficient vector, $h_{*}{ }^{11}$

$$
\begin{aligned}
h_{*} & =A(1) A(B) \operatorname{vec}\left(\left[H^{\prime}-I_{p q}\right] \sum_{i=0}^{\infty}\left(H^{\prime}\right)^{i} \iota_{*} \iota_{m}^{\prime}\left(G^{\prime}\right)^{i}\left(\left[I_{m}-G\right]^{-1}\right)^{\prime} \iota_{m}\right), \\
& =A(1) A(B)\left(\iota_{m}^{\prime}\left[I_{m}-G\right]^{-1} \otimes\left[H^{\prime}-I_{p q}\right]\right) \sum_{i=0}^{\infty}\left[G \otimes H^{\prime}\right]^{i} \operatorname{vec}\left(\iota_{*} \iota_{m}^{\prime}\right), \\
& =A(1) A(B)\left(\iota_{m}^{\prime}\left[I_{m}-G\right]^{-1} \otimes\left[H^{\prime}-I_{p q}\right]\right)\left[I_{m p q}-G \otimes H^{\prime}\right]^{-1}\left(\iota_{m} \otimes \iota_{*}\right) .
\end{aligned}
$$

This definition of the restricted coefficient vector in (12) provides a closed form solution for the linear decision rule under polynomial frictions, and a summary of differences between the unrestricted regression coefficients in a conventional error correction and the tightly restricted coefficients of the information vector, $z_{t-1}$, in a generalized error correction.

Finally, equation (11) indicates the friction parameters of the generalized rational error correction are collected in $A(1)$ and $A^{*}($.$) . This separable format is convenient for maximum$ likelihood estimation by an iterative sequence of linear regressions, as discussed in the Appendix.

\section{II.2 Higher-Order Euler Equations due to Polynomial Frictions}

As noted earlier, standard rationalizations of the linear, second-order Euler equation are based on the assumption of: (1) quadratic costs of adjusting the level of the decision variable, or (2) a discrete geometric distribution of random delays in adjustments of the decision variable. Polynomial extensions of these two prior specifications are discussed.

\section{Adjustment costs on weighted averages of decision variables}

One class of generalized frictions is associated with agent efforts to smooth weighted averages of current and lagged values of decision variables. This smoothing is represented by quadratic penalties on $C(L) y_{t}$, where $C(L)$ is a $m$-order polynomial in the lag operator, $C(L)=\sum_{j=0}^{m} c_{j} L^{j}$, and $C(1)=0$.

Agents choose a sequence of decision variables that minimize the criterion, $\chi_{t}$, defined by a

\footnotetext{
${ }^{11}$ The column stack of the product of three matrices is denoted by $\operatorname{vec}(A B C)=\left(C^{\prime} \otimes A\right) \operatorname{vec} B$, where $\otimes$ denotes the Kronecker product.
} 
second-order expansion of profits or utility around the path of equilibrium settings,

$$
\chi_{t}=E_{t}\left\{\sum_{i=0}^{\infty} B^{i}\left[c_{0}^{\prime}\left(y_{t+i}-y_{t+i}^{*}\right)^{2}+\left(C(L) y_{t+i}\right)^{2}\right]\right\}
$$

The associated Euler equation is a $2 m$-order equation in the lead and lag operators,

$$
\begin{aligned}
0 & =E_{t}\left\{\left[c_{0}^{\prime}+s_{0}+\sum_{k=1}^{m} s_{k}\left(L^{k}+(B F)^{k}\right)\right] y_{t}-c_{0}^{\prime} y_{t}^{*}\right\} \\
& =E_{t}\left\{A(B F) A(L) y_{t}-A(B) A(1) y_{t}^{*}\right\}
\end{aligned}
$$

where the $s_{k}$ coefficients in the first line of (14) are defined by coefficients of the friction polynomial, $C(L)$.

$$
s_{k}=\sum_{j=0}^{m-k} c_{j} c_{j+k} B^{j}, \quad k=0,1, \ldots, m
$$

Because the extended Euler equation in the first line of (14) is symmetric in $L$ and $B F$, the equation is unaffected if these two operator expressions are interchanged. This, in turn, implies that a solution of the characteristic equation of the Euler equation, say $\lambda^{-1}$, is also accompanied by the reciprocal solution, $B \lambda$. Consequently, the characteristic equation can be factored as shown in in the second line of equation (14). The format of this Euler equation is the same as that shown earlier in equation (1), except the factor polynomials are now explicitly identified as $m$-order polynomials.

The criterion and second-order Euler equation associated with the standard specification that quadratic costs apply only to changes in the level of the decision instrument are nested in equations (13) and (14), respectively, for the standard prior assumption that $m=1$.

\section{Smoothing levels and differences}

In a frequent interpretation of higher-order Euler equations, the decision variable, $y_{t}$, is an asset stock, and adjustment costs may be applicable not only to changes in the level of the asset but also changes in the first-difference. An example is optimal inventory planning, where $y_{t}$ indicates the inventory stock at the end of period $t$. The change in inventories, $(1-L) y_{t}$, equals production less sales. Given exogenous sales, the assumption of quadratic costs on the level of production implies a quadratic penalty on changes in the planned level of inventory, $c_{1}\left((1-L) y_{t}\right)^{2}$. Similarly, quadratic costs associated with changes in the rate of production can be represented by a quadratic smoothing penalty on changes in the planned first-difference of the inventory stock, $c_{1}\left((1-L)^{2} y_{t}\right)^{2}$. Thus, in the example of inventory modeling, it is not uncommon to assume polynomial frictions of 
the general form, $\sum_{j=1}^{2} c_{j}\left((1-L)^{j} y_{t+i}\right)^{2} .^{12}$

A generalized criterion for smoothing levels and higher-order differences, $(1-L)^{k} y_{t}$, in decision variables is

$$
\chi_{t}=E_{t}\left\{\sum_{i=0}^{\infty} B^{i}\left[c_{0}^{\prime}\left(y_{t+i}-y_{t+i}^{*}\right)^{2}+\sum_{k=1}^{m} c_{k}\left((1-L)^{k} y_{t+i}\right)^{2}\right]\right\},
$$

with the associated $2 m$-order Euler equation, $E_{t}\left\{c_{0}^{\prime}\left(y_{t}-y_{t}^{*}\right)+\sum_{k=1}^{m} c_{k}[(1-L)(1-B F)]^{k} y_{t}\right\}=0$.

\section{Smoothing weighted averages}

A second generalization is the case where quadratic penalties are associated with weighted moving averages of the decision instrument. For example, let $y_{t}$ denote new labor hires by a firm in period $t$. Suppose various job families within the firm require different durations of training by supervisors, and the number of employees occupied by training in a given period is represented by a fixed distribution of recent vintages of new hires, $c_{0} y_{t}+\ldots+c_{m-1} y_{t-m+1}$. Costs associated with variations in the rate of training may be approximated by the quadratic penalty, $\left(\left(c_{0}+\left(c_{1}-\right.\right.\right.$ $\left.\left.\left.c_{0}\right) L+\ldots+\left(c_{m-1}-c_{m-2}\right) L^{m-1}-c_{m-1} L^{m}\right) y_{t}\right)^{2}$, which is a restatement of the polynomial friction specification in equation (13). ${ }^{13}$

Another variation is the extension of quadratic penalties from smoothed one-period changes in the level of the decision variable, $(1-L) y_{t+i}$, to smoothed changes in moving averages, $(1-$ $L) \sum_{j=0}^{k-1} y_{t+i-j}=\left(1-L^{k}\right) y_{t+i}$. Examples include seasonal or term contracts where some costs are associated with one-period averages, others with two-period averages, and so on. The criterion in this instance takes the form,

$$
\chi_{t}=E_{t}\left\{\sum_{i=0}^{\infty} B^{i}\left[c_{0}^{\prime}\left(y_{t+i}-y_{t+i}^{*}\right)^{2}+\sum_{k=1}^{m} c_{k}\left(\left(1-L^{k}\right) y_{t+i}\right)^{2}\right]\right\}
$$

with the associated $2 m$-order Euler equation, $E_{t}\left\{c_{0}^{\prime}\left(y_{t}-y_{t}^{*}\right)+\sum_{k=1}^{m} c_{k}\left[\left(1-L^{k}\right)\left(1-B^{k} F^{k}\right)\right] y_{t}\right\}=0$.

\section{Stochastic response delays}

Given the tractability of linear first-order conditions, the quadratic adjustment cost specification is widely used to characterize optimal adjustment. Applications include decision variables such as nominal prices, extending from the seminal paper by Rotemberg (1982) to the recent example of Hairault and Portier (1993), although the assumption of strictly increasing costs in the size of price

\footnotetext{
${ }^{12}$ See Hall, Henry, and Wren-Lewis (1986), Callen, Hall, and Henry (1990), and Cuthbertson and Gasparro (1993).

${ }^{13}$ In all examples, note that linear cost components can be accommodated by redefining the equilibrium target, $y_{t}^{*}$, of the relevant decision variable.
} 
adjustments is often disputed. However, as noted by Rotemberg (1996), the aggregate response arising from the quadratic adjustment cost model is equivalent to the aggregate adjustment of agents subject to random decision delays drawn from an exponential distribution, as proposed by Calvo (1983). Although it appears to have received little attention outside the field of dynamic pricing, the stochastic delay model would appear to be a useful framework for modeling adjustments in other market contexts when agent responses are dependent on unpredictable transmissions of decisions, such as distributed production or communication networks. ${ }^{14}$

In a discrete-time implementation of the stochastic delay approach, each agent $j$ controls a decision variable, $y_{j, t}$, with the associated equilibrium trajectory, $y_{j, t}^{*}$. When adjustment of a decision variable occurs, the movement to equilibrium is complete but the timing of adjustment is stochastic. The probability of an agent adjustment in the $i$ th period of the planning horizon, having not adjusted in the $i-1$ preceding periods, is $r_{i}$. The schedule of future adjustment probabilities is represented by the lead polynomial, $r(F)=r_{0}+r_{1} F+r_{2} F^{2}+\ldots$, where the $r_{i}$ are nonnegative and $r(1)=1$. Using a discrete geometric distribution as the analogue of the exponential response distribution in Calvo (1983), the generating function is $r(F)=A(1) A(F)^{-1}$, where $A($. ) is the first-order polynomial, $A(F)=(1-\lambda F)$.

Given the constraint that the decision variable must remain at the level selected, say $\vec{y}_{j, t}$, until the next allowable adjustment period, the optimal setting that minimizes the expected sum of squared deviations from the discounted path of equilibrium settings is $E_{t}\left\{\vec{y}_{j, t}\right\}=E_{t}\left\{r(B F) y_{j, t}^{*}\right\}$. Using simple sum aggregation, the aggregate of decision variables adjusted in $t$ is $E_{t}\left\{\vec{y}_{t}\right\}=$ $E_{t}\left\{r(B F) y_{t}^{*}\right\}$. The aggregate decision variable is a normalized average of current and past vintage decisions that survive in $t$. In the example of a geometric delay distribution, the survival probability in $t$ of a past decision variable setting from $t-i$ is proportional to $r_{i} \cdot{ }^{15}$ Thus, the generating function for the normalized survival probabilities over an infinite horizon is $r(L)$, and the aggregate decision variable in period $t$ may be represented by

$$
\begin{aligned}
E_{t}\left\{y_{t}\right\} & =r(L) E_{t}\left\{\vec{y}_{t}\right\}, \\
& =r(L) E_{t}\left\{r(B F) y_{t}^{*}\right\} .
\end{aligned}
$$

The lag polynomial, $r(L)$, remains to the left of the expectations operator on the right-hand-side of (17) to ensure that the lagged expectations embedded in past decisions are represented in

\footnotetext{
${ }^{14}$ Effects of costly and stochastic communications in distributed production are discussed in Board and Tinsley (1996). See also Bertsekas and Tsitsiklis (1989) for representative configurations of communication networks.

${ }^{15}$ The hazard function, the ratio of the adjustment probability, $r_{i}$, to the survival probability at lag $i$, is constant for the univariate geometric distribution, Johnson, Kotz, and Kemp (1993).
} 
the current aggregate, $y_{t} .{ }^{16}$ Replacing the generating functions by the polynomial components yields the analogue to the familiar second-order decision rule for the aggregate decision variable, $E_{t}\left\{A(L) y_{t}\right\}=E_{t}\left\{A(1) A(B) A(B F)^{-1} y_{t}^{*}\right\}$.

\section{Aggregated delay schedules}

In principle, the choice of the appropriate stochastic delay distribution should be an empirical issue. Remaining within the polynomial frictions framework of this paper, the approach suggested below considers higher-order polynomial approximations of more general stochastic delay distributions. As indicated, these generalizations can be interpreted as convolutions of component geometric distributions.

It is unlikely that agents have perfect information about the distribution of delays or stochastic congestion in future decisions. Suppose, for example, agents may be confronted by a "low-cost" response distribution, $r_{1}(F)$, or a "high-cost" response distribution, $r_{1}(F)$, where the expected response lag from the first distribution is smaller than that of the second. However, draws from either delay distribution are random. In this example, the generating function of the effective response probabilities is the product of the generating functions of the component response probabilities, $r(F)=r_{1}(F) r_{2}(F) .{ }^{17}$

More generally, in the case of random aggregation over $m$ geometric response schedules, the aggregate reset of decision variables adjusted in $t$ is $E_{t}\left\{\vec{y}_{t}\right\}=E_{t}\left\{\prod_{j=1}^{m} r_{j}(B F) y_{t}^{*}\right\}$. As in the case of a univariate geometric distribution, a constant-hazard approximation permits the survival distribution of past vintage decisions to be represented by the polynomial generating function of the stochastic delays, $\prod_{j=1}^{m} r_{j}(L) .{ }^{18}$ Thus, under an $m$-order polynomial stochastic delay distribution,

\footnotetext{
${ }^{16}$ As discussed in Taylor (1993), some model specifications and instrumental methods of estimating decision rules move the equivalent of the lag polynomial, $r(L)$, inside the expectation operator.

${ }^{17}$ If $v$ and $w$ are non-negative independent random variables, the generating function of the convolution, $v+w$, is the product of the generating functions of $v$ and $w$, Feller (1968).

${ }^{18}$ The mean absolute error of constant-hazard approximations of quarterly survival probabilities is about .02 percentage points for the first sixteen lags in the empirical decision rules using polynomial frictions discussed in the next section. The reason for the relatively modest approximation errors can be shown using a partial fractions representation of the approximation error. Denote the partial fractions expansion of an $m$-order polynomial generating function by: $A(1) A(L)^{-1} \equiv \sum_{j=1}^{m} \alpha_{j}\left(1-\lambda_{j}\right)\left(1-\lambda_{j} L\right)^{-1}$, where the $\lambda_{j}$ denote the characteristic roots of $A(L)$. The error of the constant-hazard approximation of the survival probability at lag $i$ is $\sum_{j=1}^{m} \alpha_{j} \bar{\lambda}^{-1}\left(\lambda_{j}-\bar{\lambda}\right) \lambda_{j}^{i-1}$, where $\bar{\lambda} \equiv S_{s}\left(1+S_{s}\right)^{-1}$, and $S_{s}$ denotes the sum of the survival probabilities. In the case of the univariate geometric distribution, $\bar{\lambda}$ is equal to the single root, and the approximation error is zero. In the case of convoluted geometric distributions with a single dominant root, as with empirical examples in this paper, $\bar{\lambda}$ is generally very close to the modulus of the dominant root. In addition, error components associated with smaller roots decay rapidly with lag $i$ because the spread for a smaller root, $\lambda_{j}-\bar{\lambda}$, is scaled by powers of that root, $\lambda_{j}^{i-1}$.
} 
the aggregate decision variable in period $t$ is represented by

$$
E_{t}\left\{y_{t}\right\}=\prod_{j=1}^{m} r_{j}(L) E_{t}\left\{\prod_{j=1}^{m} r_{j}(B F) y_{t}^{*}\right\} .
$$

Substituting in the component polynomials of the generating functions for the stochastic delay and survival probabilities yields a solution for the aggregate decision variable that is identical to that derived earlier for the decision rule under polynomial frictions

$$
E_{t}\left\{A(L) y_{t}\right\}=E_{t}\left\{A(1) A(B) A(B F)^{-1} y_{t}^{*}\right\}
$$

where the component polynomials, $A(L)$ and $A(B F)$, are $m$-order.

\section{Empirical Examples of Rational Error Corrections for Industry Pricing}

Empirical contrasts of second-order and higher-order rational error corrections are discussed in this section. The examples used are pricing decision rules of six SIC two-digit manufacturing industries: textiles, lumber, rubber \& plastics, primary metals, motor vehicles, and scientific instruments. ${ }^{19}$ In addition to an expected difference in statistical fits, the rational expectation overidentifying restrictions are rejected by all but one of the second-order decision rules and by none of the higher-order rules.

\section{III.1 The Equilibrium Price}

The equilibrium $\log$ price of the output of industry $j$ with $s_{j}$ identical producers is represented by

$$
p_{j}^{*}=\mu_{j}+m c_{j},
$$

where $\mu_{j}$ is the $\log$ markup by producers and $m c_{j}$ is the log of marginal cost. Ignoring strategic considerations, the markup is $\mu_{j}=-\log \left(1-\frac{1}{s_{j} \eta_{j}}\right)$, where $\eta_{j}$ is the price elasticity of demand, and the monopoly and competitive solutions are obtained as $s_{j} \rightarrow 1$ or $s_{j} \rightarrow \infty$. Gross production is Cobb-Douglas in both purchased materials and rented services of primary factors. Also, returns to scale are constant so that the log of marginal cost is proportional to the weighted average of log input prices,

$$
m c_{j} \propto \theta_{j}^{c} p_{j}^{c}+\theta_{j}^{i} p_{j}^{i}+\theta_{j}^{v} p_{j}^{v}
$$

\footnotetext{
${ }^{19}$ Motor vehicles is a large subset of the SIC two-digit industry, transportation equipment.
} 
where $p_{j}^{c}$ is the log price of primary commodity production inputs, $p_{j}^{i}$ is the log price of intermediate materials purchased from other industries, $p_{j}^{v}$ is the log unit cost of value added in the $j$ industry, and $\theta_{j}^{c}+\theta_{j}^{i}+\theta_{j}^{v}=1$.

As indicated in (21), input price regressors are specific to industry $j$ and constructed from input-output weightings of industry producer prices. Industry producer prices at the SIC two-digit level of aggregation are generally available only from the mid-1980s, and industry prices in earlier periods were assembled from specific commodity prices, often at lower levels of aggregation. The industry $\log$ unit cost of primary factors, $p_{j, t}^{v}$, was estimated by the log of hourly earnings, $w_{j, t}$, less the log of trend productivity, $\rho_{j, t}$. The latter was constructed from smoothed estimates of the $\log$ of industry industrial production less the log of industry employment hours.

Industry producer prices in the U.S. do not reject the hypothesis of difference-stationarity over postwar samples. A common format was used to explore cointegration constructions of the equilibrium price of each industry

$$
p_{j, t}^{*}=c_{0}+\theta_{j}^{c} p_{j, t}^{c}+\theta_{j}^{i} p_{j, t}^{i}+\theta_{j}^{v} p_{j, t}^{v}+c_{1} \rho_{t}+c_{2} t
$$

Given data limitations of the trend productivity estimates, both industry log productivity trends, $\rho_{j, t}$ and time trends, $t$, were added as additional regressors, and the intercept, $c_{0}$ contains both the log margin, $\mu_{j}$, as well as proportional mean errors in measurements of unit cost inputs. The relevant industry input share weights, $\left(\theta_{j}^{c}, \theta_{j}^{i}, \theta_{j}^{v}\right)$, are displayed in the initial columns of Table 1. These share weights are not estimated but defined by benchmark input-output estimates, obtained by manipulating the Bureau of Economic Analysis (1991) industry use and make tables.

As shown in the columns headed by $f(t)$ in Table 1 , additional trend productivity regressors were required for cointegration in three industries. As noted above, the log price of primary factors already incorporates trend productivity, $p_{j}^{v} \equiv w_{j}-\rho_{j}$. Because this assigns a weight of $-\theta^{v}$ to $\rho_{j}$, the additional positive coefficients lower the effective contribution of the trend productivity constructions. Finally, as shown in the last column of Table 1, the hypothesis that the cointegrating discrepancy, $p_{j, t}-p_{j, t}^{*}$ is $I(1)$ is rejected at the $90 \%$ confidence level or higher for all industries.

\section{III.2 Empirical Estimates of Pricing Decision Rules under Geometric Frictions}

Table 2 presents summary statistics for second-order pricing rules of the six manufacturing industries, estimated under the prior of geometric frictions. Estimated parameters of the industry decision rules and VAR forecast model parameters were obtained by the maximum likelihood estimator described in the Appendix. ${ }^{20}$

\footnotetext{
${ }^{20}$ Industry prices are quarterly averages of monthly, seasonally unadjusted series from the US Bureau of Labor database on commodity and industry producer prices for the 1954-1995 sample. As noted earlier, the equilibrium
} 
The estimated error correction coefficients, $A(1)$ in Table 2 , indicate the average quarterly reduction rates planned for the price "gap," $p_{t-1}-p_{t-1}^{*}$, of each industry. The proportion of explained variation in quarterly price changes can be substantial, with $R^{2}$ in three industries ranging from .3 to .6. The row in Table 2 labeled $\Delta R^{2}(\%)$ indicates that for four industries, the modal source of explained variation is the sample variability of industry forecasts of future equilibrium prices, as captured by the rational forecast term, $h_{*}^{\prime} z_{t-1}$. Table 2 also contains the estimated mean lag of producer responses to unexpected shocks and the estimated mean lead of responses to anticipated events. The mean lead of the industry planning horizon is typically smaller than the mean lag response due to discounting of forward events.

Three characteristics of these estimated equations suggest significant dynamic specification problems. First, the mean lag responses appear to be unusually large relative to previous estimates of response lags for manufacturing prices. ${ }^{21}$ Second, serial independence of the residuals is rejected for all but one industry at $95 \%$ confidence levels. Although it is possible that producers may have serially correlated information that has not been included in the industry forecast models, it is plausible also that residual correlations could be due to misspecifications of the frictions in producer responses.

A final indication of potential misspecifications is indicated in the bottom row of Table 2. This row, labeled $L R\left(h_{*} \mid z_{t-1}\right)$, lists the rejection probabilities of a likelihood ratio test to determine if the data prefers an unrestricted forecast model of forward equilibrium price changes to the rational forecasts embedded in the geometric frictions version of rational error correction. With one exception (motor vehicles), the rational expectations overidentifying restrictions are rejected at $99 \%$ confidence levels.

\section{III.3 Empirical Estimates of Pricing Decision Rules under Polynomial Frictions}

Estimates of the industry pricing rules under the polynomial generalization of frictions are listed in Table 3. Because the conventional two-root decision rule, $m=1$, is nested in the generalized frictions model, it is interesting to note that additional lags of the dependent variable are always

price forecast model for each industry is a VAR containing the equilibrium price and the prices of production inputs. Although seasonality is not pronounced in most industry prices (one exception is motor vehicles, as noted later), all industry VARs contained at least four lags in regressors, and seasonal dummies were added to all VAR and error correction equations. To reduce space, estimates of equation intercepts and seasonal dummy coefficients are not reported in the tables. In all equations presented here, the quarterly discount factor, $B$, was set to .98 , approximating the postwar annual real return to equity of about $8 \%$; empirical results are not noticeably altered by moderate variations in $B$.

${ }^{21}$ In analysis of the Stigler-Kindahl data of producers' prices, Carlton (1986) reports an average adjustment frequency of about once a year. Reduced form regressions by Blanchard (1987, Table 8) for the U.S. manufacturing price aggregate indicate a mean lag of about two quarters. By contrast, the levels friction model in Rotemberg (1982) suggests a mean lag of about 12 quarters for the U.S. GDP deflator. 
significant in the industry pricing models, generally consistent with polynomial components of order $m=2$ or $m=3 .^{22}$ In the case of motor vehicles, the preferred specification is $m=$ 5 , requiring four lags of the dependent variable. This is due to a significant seasonal pattern in the producer price of motor vehicles which could not be adequately captured by fixed seasonal dummies.

Without exception, all of the problems noted for the estimated decision rules under geometric frictions in Table 2 are eliminated under polynomial frictions. The percentage of explained variation, $R^{2}$, is considerably higher for most industries in Table 3; mean lags are more plausible; the assumption of serially independent residuals is retained in all industries; and the rejection probabilities in the bottom row in Table 3 indicate that the rational expectations overidentifying restrictions are not rejected at confidence levels of $95 \%$ or higher. The latter is noteworthy because rejections of rational expectations overidentifying restrictions are often interpreted as evidence of non-rational forecasting by agents or of inadequate specifications of agent forecast models of forcing terms. Because the only difference between industry model specifications used in the side-by-side comparisons of Table 2 and Table 3 is the degree of the Euler equation polynomials, $m$, the culprit, at least in these examples and for the statistical properties considered, is rigid priors on the specification of dynamic frictions.

More intuitive insights into the dynamic effects of the higher-order lag and lead polynomials are obtained by rearranging the Euler equation to define the current period response weights to lags and expected leads of the forcing term, $E_{t}\left\{p_{t+i}^{*}\right\}$, implied by the industry decision rules,

$$
\begin{aligned}
E_{t}\left\{p_{t}\right\} & =E_{t}\left\{A(1) A(L)^{-1} A(B) A(B F)^{-1} p_{t}^{*}\right\} \\
& =E_{t}\left\{\sum_{i=-\infty}^{\infty} w_{i} p_{t+i}^{*}\right\}
\end{aligned}
$$

where negative subscripts, $i<0$, denote responses to lagged events and positive subscripts, $i>0$, responses to anticipated events. The lag and lead weights of the six estimated industry decision rules are displayed in the panels of Figure 1. The dotted lines are the friction weights generated by the two-root decision rules $(m=1)$ reported in Table 2 and the solid lines are the friction weights associated with the $2 m$-root decision rules $(m>1)$ shown in Table 3 .

Several effects of the generalization of frictions are apparent from the plots of the industry friction weights in Figure 1. In each panel, the vertical line is positioned in the current period

\footnotetext{
${ }^{22}$ This is not an isolated finding. Every macroeconomic aggregate to which the generalized frictions model was fit in the FRB/US macroeconomic model also rejected the conventional prior that $m=1$, vid. Brayton and Tinsley (1996). As discussed in a recent literature survey by Taylor (1997), many studies of empirical staggered contract models for wages do not support geometric response schedules, including an estimated bimodal distribution of contract lengths in Levin (1991).
} 
$(i=0)$. The mean lag of responses to unanticipated events is captured by the weighted average of lags using the friction weights to the left of center. The friction weights are nearly symmetric about the current period with the mean lead, associated with weights to the right of center, slightly smaller than the mean lag due to the discounting of future events. Thus, the net mean response lag to perfectly anticipated events is small for most industries.

Larger mean leads require longer planning horizons and are characteristic of the flatter friction weight distributions indicated by the dotted lines in Figure 1 for the two-root decision rules, $m=1$. Thus, vertical distances between the two sets of friction weight distributions in each panel are indicative of differences between the industry mean leads of Table 2 and the corresponding mean leads of Table 3.

As shown in the panels of Figure 1, relatively low-order friction polynomials, $A(B) A(B F)^{-1}$, can generate a variety of flexible shapes, including the seasonal weights at distances of \pm 4 quarters indicated for the motor vehicles industry, SIC 371. Some estimated friction distributions are relatively flat for several quarters, while others fall off rapidly from the modal weight in the current quarter. The plots in Figure 1 do not support the two-sided geometric distribution prior that is consistent with two-root decision rules, $m=1$. In almost all industries, the drawback of a two-sided geometric response schedule is an inability to capture relatively stronger industry responses to events in a one - or two-quarter neighborhood of the current quarter.

\section{Cyclical Variations in Pricing Margins}

Thus far, specification of the desired industry price settings has proceeded under the assumption that relevant arguments are difference-stationary, with estimation of industry "target" paths, $p_{t}^{*}$, by cointegration. However, economic theory may suggest additional stationary variables as possible arguments of the desired target. ${ }^{23}$ If there is prior information that agents' perceptions of the forcing terms of Euler equations are significantly influenced by additional variables, this prior information should be introduced into the model to avoid possible distortions in estimated frictions. An example is useful to illustrate how the distinction between friction and forecast parameters is maintained for trial arguments of the forcing term by imposing dynamic friction restrictions.

In the present example of a price markup model, cyclical indicators such as industry capacity utilization rates may capture variations in planned margins, $\mu_{t}$, due to boom or bust pricing strategies or cyclical movements in the price elasticity of demand. The Euler equation for industry price is restated to include the effect of current and lagged industry utilization rates, $u_{t-i},{ }^{24}$ on the

\footnotetext{
${ }^{23}$ As discussed by Wickens (1996), economic theory is required for structural interpretations of cointegrations.

${ }^{24}$ Industry utilization rates are constructed by the FRB staff from surveys of capacity utilization, see Raddock (1985). Log industry utilization rates are stationary, and the error correction responses of capacity output are either insignificant or an order of magnitude smaller than that of industry output. Sample means are removed so $u_{t}$ can be
} 
current price target,

$$
E_{t}\left\{A(B F) A(L) p_{t}-A(B) A(1)\left[p_{t}^{*}+D(L) u_{t}\right]\right\}=0,
$$

where $p_{t}^{*}$ continues to denote $\mathrm{I}(1)$ arguments of the equilibrium target, and $D(L)$ is an $m^{\prime}$-order polynomial in $L$. It is convenient to assume $m^{\prime}=1$, which is the minimal order necessary to distinguish between pricing effects of changing utilization rates and effects of higher or lower levels of capacity utilization, $D(L)=d_{0}+d_{1} L$.

Multiplying through by the inverse of the lead polynomial, $A(B F)^{-1}$, and substituting in forecasts from the agents' information set, $z_{t-1}$, defines the augmented rational error correction where the industry price decision rule now contains an infinite-horizon forecast of forward industry utilization rates, discounted by the $m$ eigenvalues contained in the frictions companion matrix, $G$. Using the simplifying operations discussed earlier, the closed-form of the extended rational error correction solution is

$$
E_{t}\left\{\Delta p_{t}\right\}=-A(1)\left(p_{t-1}-p_{t-1}^{*}\right)+A^{*}(L) \Delta p_{t-1}+h_{*}^{\prime} z_{t-1}+\sum_{k=0}^{1} d_{k} h_{u_{k}}^{\prime} z_{t-1},
$$

The additional coefficient vectors, $h_{u_{k}}(k=0,1)$, define discounted sums of the expected forward path of the industry utilization rate,

$$
\begin{aligned}
& h_{u_{0}}=A(1) A(B)\left[\iota_{m}^{\prime} \otimes H^{\prime}\right]\left[I_{m n}-G \otimes H^{\prime}\right]^{-1}\left(\iota_{m} \otimes \iota_{u_{0}}\right), \\
& h_{u_{1}}=A(1) A(B)\left[\iota_{m}^{\prime} \otimes I_{n}\right]\left[I_{m n}-G \otimes H^{\prime}\right]^{-1}\left(\iota_{m} \otimes \iota_{u_{1}}\right),
\end{aligned}
$$

where the $n \times 1$ selector vectors, $\iota_{u_{k}}$, locate $u_{t-k}$ in the information vector, $z_{t}$, now extended to include current and lagged values of the industry utilization rate. Because industry log utilization rates are stationary, the restricted coefficient vectors in (26) differ somewhat from that derived for forecasts of difference-stationary trend prices, $h_{*}$, in (12).

Effects of adding industry utilization rates to the rational error correction are reported in Table 4. The rejection probabilities in the row labeled $L R(D(L))$ indicate that expected forward utilization rates are a significant determinant of pricing at a $90 \%$ level of confidence in three of the six industries. Cyclical markup effects associated with the level of the industry utilization rate are indicated in the next row of Table 4, labeled $D(1)$. Procyclical margins are indicated for primary metals (SIC 33) and countercyclical margins for motor vehicles (SIC371).

All significant features of the rational error corrections in Table 3 are retained in Table 4, including serially independent residuals and nonrejection of the RE overidentifying restrictions

interpreted as industry output deviations from trend or preferred utilization. 
which are now extended to include forecasts of forward utilization rates. Thus, the polynomial frictions description of industry pricing appears to be robust to the addition of a conventional determinant of cyclical pricing.

\section{Concluding Comments}

After two decades of research in macroeconomics, the rational expectations conjecture is a fixture in theoretical macroeconomic models but is routinely rejected in empirical macroeconomic models that test the associated overidentifying restrictions. Rather than indicting the rational expectations assumption, it appears that the main culprit may be the arbitrary tight prior used to characterize dynamic frictions in macroeconomic models.

The workhorse of macroeconomic descriptions of rational dynamic behavior is the conventional linear decision rule with two characteristic roots, where one determines the geometric discount factor of anticipated events and the other provides a geometric description of lagged responses to unanticipated shocks. The two-sided geometric lead and lag response schedules are generally motivated by a geometric frictions prior where agents aim to smooth levels of activity or are subject to geometric random delays. Although it leads to tractable models of economic behavior, the geometric frictions prior is not based on compelling economic theory and is usually rejected by macroeconomic data.

An alternative specification of polynomial frictions is suggested in this paper which appears to eliminate many of the empirical drawbacks of the conventional frictions specification. The generalized frictions specification can be interpreted as the result of agents that smooth linear combinations of current and lagged actions or a consequence of convoluted geometric distributions of stochastic delays in decisions.

Polynomial frictions lead to higher-order Euler equations whose decision rules are solved generally by numerical techniques. A method of obtaining closed-form solutions is presented that uses two simple, first-order companion systems: a lead system for the forward planning required when agent actions are restricted by frictions; and a lag system for the agents' forecast model of the Euler equation forcing term. A tractable method of maximum likelihood estimation by a sequence of regressions is outlined in the Appendix.

Empirical models of producer pricing are estimated for six manufacturing industries. The second-order decision rule implied by the geometric frictions prior is nested within the polynomial frictions specification and rejected by the data for all industries. The decision rules based on geometric frictions had poor empirical properties, including overstatement of mean lags, strong residual correlations, and rejections of rational expectation restrictions. Rational error corrections 
using the generalized friction specification eliminated these empirical shortcomings, including the rejection of rational expectations restrictions. The estimated generalized friction models of industry pricing generally required fourth-order or sixth-order decision rules.

Polynomial descriptions of frictions define a rich class of rational error correction specifications. The empirical applications indicate that higher-order decision rules provide empirical fits comparable to reduced-form error corrections and, unlike the latter, provide useful distinctions between lags due to forecasts of market events and lags due to constrained agent responses to these forecasts. 


\section{References}

Anderson, G. and G. Moore. (1985). “A Linear Algebraic Procedure for Solving Linear Perfect Foresight Models.” Economic Letters, 17, 247-52.

Abel, A. and O. Blanchard. (1986). "The Present Value of Profits and Cyclical Movements in Investment." Econometrica, 54, 249-73.

Anderson, E., L. Hansen, E. McGrattan, and T. Sargent. (1996). "Mechanics of Forming and Estimating Dynamic Linear Economies." in H. Amman, D. Kendrick and J. Rust (eds.), Handbook of Computational Economics I, Amsterdam: Elsevier Science, 171-252.

Bertsekas, D. and J. Tsitsiklis. (1989). Parallel and Distributed Computation, Englewood Cliffs: Prentice Hall.

Blanchard, O. (1983). "The Production and Inventory Behavior of the American Automobile Industry." Journal of Political Economy, 91, 365-400.

Blanchard, O. (1987). "Aggregate and Individual Price Adjustment." Brookings Papers on Economic Activity, 57-109.

Board, R. and P. Tinsley. (1996). "Smart Systems and Simple Agents." in Computational Economic Systems, Gilli, M. (ed.) Dordrecht: Kluwer Academic Publishers, 51-79.

Brayton, F. and P. Tinsley (1996). "A Guide to FRB/US: A Macroeconomic Model of the United States." Federal Reserve Board, Finance and Economics Discussion Series 1996-42.

Bryant, R., P. Hooper, and C. Mann (eds.) (1993). Empirical Evaluation of Alternative Policy Regimes. Washington: The Brookings Institution.

Bureau of Economic Analysis. (1991). The 1982 Benchmark Input-Output Accounts of the United States. Washington: U.S. Government Printing Office.

Callen, T., S. Hall, and S. Henry. (1990). "Manufacturing Stocks: Expectations, Risk and Co-Integration.” Economic Journal, 100, September, 756-72.

Calvo, G. (1983). "Staggered Prices in a Utility-Maximizing Framework.” Journal of Monetary Economics, 12, 383-98.

Carlton, D. (1986). "The Rigidity of Prices.” American Economic Review, September, 637-58.

Christiano, L., M. Eichenbaum, and C. Evans. (1994). "Identification and the Effects of Monetary Policy Shocks.” Federal Reserve Bank of Chicago Working Paper 94-7, May.

Cuthbertson, K. and D. Gasparro. (1983). "The Determinants of Manufacturing Inventories in the UK." Economic Journal, 103, November, 1479-92.

Epstein, L. and M. Denny. (1983). "The Multivariate Flexible Accelerator Model: Its Empirical Restrictions and An Application to U.S. Manufacturing." Econometrica, 51, May, 647-674.

Ericsson, N. and D. Hendry. (1991). "Modeling the Demand for Narrow Money in the United Kingdom and the United States." European Economic Review, 35, May, 833-86.

Ericsson, N. and J. Irons. (1995). "The Lucas Critique in Practice: Theory Without Measurement." in Macroeconometrics: Developments, Tensions, and Prospects, K. Hoover (ed.) Boston: Kluwer Academic Publishers.

Feller, W. (1968). An Introduction to Probability Theory and Its Applications, 3rd edition. New York: John Wiley \& Sons. 
Frisch, R. (1936). "On the Notion of Equilibrium and Disequilibrium." Review of Economic Studies, III, February, 100-5.

Hairault, J. and F. Portier. (1993). "Money, New-Keynesian Macroeconomics and the Business Cycle." European Economic Review, 37, December, 1533-68.

Hall, S, S. Henry, and S. Wren-Lewis. (1986). "Manufacturing Stocks and Forward-Looking Expectations in the UK." Economica, 53, November, 447-65.

Hansen, L. and T. Sargent. (1980). "Formulating and Estimating Dynamic Linear Rational Expectations Models.” Journal of Economic Dynamics and Control, February, 7-46.

Johnson, N., S. Kotz, and A. Kemp. (1993). Univariate Discrete Distributions, New York: John Wiley \& Sons.

Kydland, F. and E. Prescott. (1991). "The Econometrics of the General Equilibrium Approach to Business Cycles." Scandinavian Journal of Economics, 93(2), 161-78.

Levin, A. (1991). "The Macroeconomic Significance of Nominal Wage Contract Duration." University of California at San Diego Discussion Paper 91-08, February.

Lucas, R. (1976). "Econometric Policy Evaluation: A Critique." in "The Phillips Curve and Labor Markets," K. Brunner and A. Meltzer (eds.), Carnegie-Rochester Conference Series on Public Policy, 1, 19-46.

MacKinnon, J. (1991). “Critical Values for Cointegration Tests," in R. Engle and C. Granger (eds.), Long-Run Economic Relationships, New York: Oxford University Press, 267-76.

Meese, R. (1980). "Dynamic Factor Demand Schedules for Labor and Capital under Rational Expectations." Journal of Econometrics. 14, 141-58.

Murphy, K. and R. Topel. (1985). "Estimation and Inference in Two-Step Econometric Models." Journal of Business Economics and Statistics, 3, October, 370-9.

Muscatelli, A. (1989). "A Comparison of the 'Rational Expectations' and 'General-to-Specific' Approaches to Modelling the Demand for M1." Oxford Bulletin of Economics and Statistics, 51(4), November, 353-75.

Nickell, S. (1985). "Error Correction, Partial Adjustment and All That: An Expository Note." Oxford Bulletin of Economics and Statistics, 47, 119-29.

Pesaran, H. (1991). "Cost Adjustment under Rational Expectations: A Generalization.” Review of Economic Studies, May, 353-8.

Pindyck, R. and J. Rotemberg. (1983). "Dynamic Factor Demands under Rational Expectations." Scandinavian Journal of Economics. 85, 223-38.

Price, S. (1992). "Forward Looking Price Setting in UK Manufacturing." Economic Journal, 102, May, 497-505.

Raddock, R. (1985). "Revised Federal Reserve Rates of Capacity Utilization.” Federal Reserve Bulletin. 71, October, 754-66.

Rotemberg, J. (1982). "Sticky Prices in the United States." Journal of Political Economy, 90(6), December, 1187-1211.

Rotemberg, J. (1996). "Prices, Output, and Hours: An Empirical Analysis Based on a Sticky Price Model." Journal of Monetary Economics, 37(3), June, 505-33. 
Sargent, T. (1978). "Estimation of Dynamic Labor Demand Schedules under Rational Expectations.” Journal of Political Economy, 86, December, 1009-44.

Sargent, T. (1993). Bounded Rationality in Macroeconomics. Oxford: Clarendon Press.

Shapiro, M. (1986). "The Dynamic Demand for Capital and Labor." Quarterly Journal of Economics, 101, August, 513-42.

Sims, C. (1992). "Interpreting the Macroeconomic Time Series Facts." European Economic Review 36(5), June, 975-1011.

Swamy, P. and P. Tinsley. (1980). "Linear Prediction and Estimation Methods for Regression Models with Stationary Stochastic Coefficients.” Journal of Econometrics, 12, 103-42.

Taylor, J. (1993). Macroeconomic Policy in a World Economy, New York: Norton.

Taylor, J. (1997). "Temporary Price and Wage Rigidities in Macroeconomics: A Twenty-five Year Review." processed.

Tinsley, P. (1970). 'On Ramps, Turnpikes, and Distributed Lag Approximations of Optimal Intertemporal Adjustment.” Western Economic Journal, December, 397-411.

Tinsley, P. (1971). “A Variable Adjustment Model of Labor Demand.” International Economic Review, 12, October, 482-510.

Watson, M. (1994). "Vector Autoregressions and Cointegration." in R. Engle and D. McFadden (eds.) Handbook of Econometrics, IV, Amsterdam: Elsevier Science, 2843-2915.

White, H. (1994). Estimation, Inference and Specification Analysis, Cambridge: Cambridge University Press.

Wickens, M. (1996). "Interpreting Cointegrating Vectors and Common Stochastic Trends." Journal of Econometrics, 74, October, 255-71. 


\section{Appendix: Estimation of Rational Error Corrections}

This appendix outlines the two-stage maximum likelihood estimator for rational error corrections used for the empirical examples in this paper. The estimator requires only a sequence of regressions. Because linear rational error corrections have closed-form solutions, analytical solutions are available for all required gradients.

\section{Estimating the Rational Error Correction Decision Rule}

The assumption of rational behavior leads to overidentified decision rules whose parameters are nonlinear functions of parameters in the companion matrix of the forecast model, $H$, and parameters in the companion matrix, $G$, of the frictions polynomial, $A($.). However, the forecast model of forcing terms often can be reasonably approximated by a system that is linear in the unknown parameters. There are significant computational advantages to adopting a two-stage maximum likelihood procedure when the forecast model can be estimated by standard linear estimators. Assuming the forecast model is linear in the unknown parameters and has normally distributed forecast errors, maximum likelihood estimates of the column stack of forecast model parameters, $\hat{h}_{x}$, are obtained by a GLS estimator, or even OLS regressions if the forecast model equations have identical regressors.

Turning to the second stage of estimation, discussion will ignore estimation of unconstrained linear parameters such as intercepts and fixed seasonals. The vector of unknown friction parameters is $\theta=\left[-A(1), a_{1}^{*}, \ldots, a_{m-1}^{*}\right]^{\prime}$. Using $y_{t}$ to denote the dependent variable $\left(\Delta p_{t}\right.$ for the industry price decision rules) and assuming normally distributed description errors, the log of the marginal likelihood of $\theta$ is

$$
L_{y}(\theta)=-(T / 2) \log \sigma_{\epsilon_{y}}^{2}-(T / 2) \log (2 \pi)-\frac{1}{2 \sigma_{\epsilon_{y}}^{2}} \sum_{t=1}^{T}\left(y_{t}-\theta^{\prime} z_{y, t-1}-h_{*}^{\prime} z_{t-1}\right)^{2},
$$

where $z_{y, t-1}$ includes both the lagged error correction, $p_{t-1}-p_{t-1}^{*}$, and $m-1$ lags of the dependent variable, and $\sigma_{\epsilon_{y}}^{2} \equiv E\left[\left(y_{t}-\theta^{\prime} z_{y, t-1}-h_{*}^{\prime} z_{t-1}\right)^{2}\right]$. Maximum likelihood estimates of the friction parameters, $\hat{\theta}$, are defined by the zeroes of the gradients of (A.1) with respect to the friction parameters, $g_{y}(\hat{\theta})$, given the first-stage estimates of the forecast model coefficients, $\hat{h}_{x}$. The format of these nonlinear equations is well-suited for Gauss-Newton estimation using iterative regressions of the form,

$$
\left.\left(y_{t}-\hat{\theta}^{(i)^{\prime}} z_{y, t-1}-h_{*}^{\prime}\left(\hat{\theta}^{(i)}, \hat{h}_{x}\right) z_{t-1}\right)=\left(z_{y, t-1}+\left[\partial h_{*}^{\prime}\left(. \mid \hat{h}_{x}\right)\right) / \partial \theta\right] z_{t-1}\right)^{\prime}\left(\hat{\theta}^{(i+1)}-\hat{\theta}^{(i)}\right) .
$$


Adjusting for the Sampling Variability of the Forecast Model Parameters

As noted, forecast model parameters estimated in the first step, $\hat{h}_{x}$, are used to initialize gradients of the friction parameters in the second step. A well-known, but often ignored, consequence is that the second-step estimator understates the sampling errors of the estimated friction parameters, $\hat{\theta}$, unless account is taken of the sampling uncertainty of the first-step estimates of the forecast model parameters. Murphy and Topel (1985) cite empirical examples where uncorrected t-ratios of two-stage maximum likelihood estimators are overstated by more than $100 \%$. Analytical solutions of the correction for "generated regressor" bias in two-stage maximum likelihood estimation of rational error corrections are presented below, along with empirical estimates of the $t$-ratio corrections for the examples of industry pricing decision rules.

Using more compact notation, let $\beta$ denote the concatenation of the unknown parameters of the forecast model, $h_{x}$, and the friction parameters, $\theta$. Similarly, $g(\hat{\beta})$ will denote the stack of the relevant likelihood gradients, $g_{x}\left(\hat{h}_{x}\right)$ and $g_{y}(\hat{\theta})$. For a $T$-period sample, the mean-value theorem implies that the $\sqrt{T}$-normalization of the difference between the sample estimate, $\hat{\beta}$ and the plim, $\beta^{o}$, is provided by rearranging the first-order expansion of the gradients around $g\left(\beta^{o}\right)$,

$$
\sqrt{T}\left(\hat{\beta}-\beta^{o}\right)=\left[-\frac{1}{T} \nabla g\left(\beta^{*}\right)\right]^{-1}\left[\frac{1}{\sqrt{T}} g\left(\beta^{o}\right)\right],
$$

where $\nabla$ denotes the gradient of $g$ wrt $\beta^{\prime}$, and the rows of $\nabla g\left(\beta^{*}\right)$ are evaluated at $\beta^{*}$, on the segment connecting $\hat{\beta}$ and $\beta^{o}$. If the normalized Hessian approaches a fixed limit, $\operatorname{plim}\left[-\frac{1}{T} \nabla g\left(\beta^{*}\right)\right] \rightarrow M$, and the marginal likelihood functions satisfies standard regularity conditions then, as demonstrated in White (1994), the likelihood estimates are distributed asymptotically as the normal distribution,

$$
\sqrt{T}\left(\hat{\beta}-\beta^{o}\right) \stackrel{a}{\sim} N\left(0, M^{-1} V\left(M^{\prime}\right)^{-1}\right)
$$

where $V$ denotes the expected value of the gradient covariance, $V=E\left\{\left[\frac{1}{\sqrt{\bar{T}}} g\left(\beta^{o}\right)\right]\left[\frac{1}{\sqrt{\bar{T}}} g\left(\beta^{o}\right)\right]^{\prime}\right\}$.

An advantage of the two-stage estimation approach is that the structure of the sampling errors in $(A .3)$ is substantially simplified when the industry forecast model is not a function of the friction parameters, $\theta$. To see this, partition $M$ and $V$ to reflect the separate contributions of the forecast coefficients, $h_{x}$, and the adjustment cost parameters, $\theta$.

$$
M=\left[\begin{array}{cc}
M_{h_{x}, h_{x}^{\prime}} & M_{h_{x}, \theta^{\prime}} \\
M_{\theta, h_{x}^{\prime}} & M_{\theta, \theta^{\prime}}
\end{array}\right], \quad V=\left[\begin{array}{cc}
V_{h_{x}, h_{x}^{\prime}} & V_{h_{x}, \theta^{\prime}} \\
V_{\theta, h_{x}^{\prime}} & V_{\theta, \theta^{\prime}}
\end{array}\right] .
$$

Because the parameters of the forecast model, $h_{x}$, are not functions of the friction parameters, $\theta$, the upper right hand partition of $M$ is zero, $M_{h_{x}, \theta^{\prime}}=0$. This, in turn, implies that the inverse of 
$M$ required for equation (A.3) simplifies to

$$
M^{-1}=\left[\begin{array}{cc}
M_{h_{x}, h_{x}^{\prime}}^{-1} & 0 \\
-M_{\theta, \theta^{\prime}}^{-1} M_{\theta, h_{x}^{\prime}} M_{\theta, \theta^{\prime}}^{-1} & M_{\theta, \theta^{\prime}}^{-1}
\end{array}\right] .
$$

Substituting this partitioned inverse into $(A .3)$ yields the following expression for the asymptotic covariance of the adjustment cost parameters,

$$
\begin{aligned}
\operatorname{var}\left(\hat{\theta}-\theta^{o}\right)=M_{\theta, \theta^{\prime}}^{-1}+M_{\theta, \theta^{\prime}}^{-1}[ & M_{\theta, h_{x}^{\prime}} M_{h_{x}, h_{x}^{\prime}}^{-1} M_{\theta, h_{x}^{\prime}}^{\prime} \\
& \left.\quad-V_{h_{x}, \theta^{\prime}}^{\prime} M_{h_{x}, h_{x}^{\prime}}^{-1} M_{\theta, h_{x}^{\prime}}^{\prime}-M_{\theta, h_{x}^{\prime}} M_{h_{x}, h_{x}^{\prime}}^{-1} V_{h_{x}, \theta^{\prime}}\right] M_{\theta, \theta^{\prime}}^{-1} .
\end{aligned}
$$

The last two terms in (A.4) are zero if the residual of the rational error correction is uncorrelated with residuals of the VAR forecast model, $V_{h_{x}, \theta^{\prime}}=0$.

The nonzero partitions of $M$ are replaced with the following sample estimates:

$$
\begin{aligned}
& M_{h_{x}, h_{x}^{\prime}}=E\left[-\frac{\partial^{2} L_{x}}{\partial h_{x} \partial h_{x}^{\prime}}=E\left[g_{x}\left(h_{x}\right) g_{x}\left(h_{x}\right)^{\prime}\right] .\right. \\
& M_{\theta, \theta^{\prime}}=E\left[-\frac{\partial^{2} L_{y}}{\partial \theta \partial \theta^{\prime}}\right]=E\left[g_{y}(\theta) g_{y}(\theta)^{\prime}\right] . \\
& M_{\theta, h_{x}^{\prime}}=E\left[-\frac{\partial^{2} L_{y}}{\partial \theta \partial h_{x}^{\prime}}\right]=E\left[g_{y}(\theta) g_{y}\left(h_{x}\right)^{\prime}\right] .
\end{aligned}
$$

Components required by $(A .5)$ can be assembled from gradients and covariances produced in the first and second stages of the estimation. Analytical solutions of required gradients are indicated below.

\section{Empirical Estimates of Sampling Error Bias}

The magnitude of "generated bias" adjustments in the $t$-ratios of the estimated industry pricing rules can be gauged from Table 4. Along with the adjusted $t$-statistics in parentheses, (.) that are reported in all three tables, Table 4 also lists the unadjusted $t$-statistics from the second step estimation in brackets, [.]. Although the extent of adjustment varies, the maximum downward adjustment of $t$-ratios is around $20 \%$. An intuitive explanation for the generally modest reductions in statistical significance is that much of the forecast model uncertainty is "averaged out" over the forecast horizon by the discounted average of equilibrium price change forecasts, $h_{*}^{\prime} z_{t-1}$.

\section{Analytical Gradient Solutions}

Nonlinear interactions of the frictions parameters and the forecast model parameters are confined to the scalar summary of industry forecasts in the decision rule, $h_{*}^{\prime} z_{t-1}$. Using $n \equiv p q$ to reduce 
subscript clutter. the $n \times 1$ coefficient vector $h_{*}$ is completely defined by $H$, the $n \times n$ companion matrix of the industry forecast model, and the $m$ friction arguments, $\theta$. From (12), the restricted coefficient vector, $h_{*}$, can be partitioned into four components

$$
\begin{aligned}
h_{*} & =[A(B)][A(1)]\left[\iota_{m}^{\prime}\left(I_{m}-G\right)^{-1} \otimes\left(H^{\prime}-I_{n}\right)\right]\left[\left(I_{n m}-G \otimes H^{\prime}\right)^{-1}\right]\left[\iota_{m} \otimes \iota_{*}\right], \\
& =[A(B)][A(1)]\left[W_{1}\right]\left[W_{2}\right]\left[w_{1}\right],
\end{aligned}
$$

where the first four partitions on the last line of $(A .6)$ are functions of the unknown frictions parameters, $\theta$.

To indicate the partial derivatives with respect to the $j^{\text {th }}$ argument of the parameter vector, $\theta_{(j)}$, the following notation conventions are used. Element-by-element differentiation of vectors and matrices is represented by the relevant subscripted $\iota_{n(j)}$ vector(s). For example, the partial derivative of the $n \times 1$ vector $b$ with respect to its second element is $\partial b / \partial b_{(2)}=[0,1,0, \ldots, 0]^{\prime}=$ $\iota_{n(2)}$. Similarly, the partial derivative of the $m \times n$ of matrix B with respect to its $i j^{\text {th }}$ element is denoted by $\partial B / \partial B_{(i j)}=\iota_{m(i)} \otimes \iota_{n(j)}^{\prime}$. Two $m \times m$ transformation matrices are useful also: $T_{1}$ is an upper-triangular matrix for effecting moving-summations, with -1 in each element of the first row and 1 in each of the remaining nonzero elements; $T_{2}$ is a reverse-diagonal discounting matrix with $-B^{m-i+1}$ in the $m-i+1$ th element of the $i$ th row.

As shown in the main text, the bottom row of the $m \times m$ companion matrix, $G$, of the friction lead polynomial contains powers of the discount factor, $B$, and the parameters of the friction lag polynomial, $a^{\prime}=\left[a_{1}, a_{2}, \ldots, a_{m}\right]$. The relationship between these parameters and the friction parameters, $\theta$, in the decision rule likelihood, (A.1), is given by $\theta=T_{1} a-\iota_{m(1)}$. Denoting $g^{\prime}$ as the bottom row of $\mathrm{G}$, then it is seen that $g^{\prime}=a^{\prime} T_{2}^{\prime}=\left(\theta^{\prime}+\iota_{m(1)}^{\prime}\right) T_{1}^{\prime}-1 T_{2}^{\prime}$. In turn, the $m \times m$ matrix $G$ is defined by $G=T_{3}+\iota_{m(m)} \otimes g^{\prime}$, where $T_{3}$ is constructed by bordering $I_{m-1}$ by a column of zeroes on the left and a row of zeroes on the bottom. It follows that the partial derivative of $G$ with respect to the $j^{\text {th }}$ element of $\theta$ is, $\partial G / \partial \theta_{(j)}=\iota_{m(m)} \otimes \iota_{m(j)}^{\prime} T_{1}^{\prime-1} T_{2}^{\prime}$.

Using these definitions, analytical expressions for the gradients required by the Gauss-Newton regression in $(A .2)$ are constructed from the following partial derivatives:

$$
\begin{array}{ll}
\partial A(B) / \partial \theta_{(j)} & =-\iota_{m(m)}^{\prime} T_{2} T_{1}^{-1} \iota_{m(j)} \\
\partial A(1) / \partial \theta_{(j)} & =\iota_{m(m)}^{\prime} T_{1}^{-1} \iota_{m(j)}, \\
\partial W_{1} / \partial \theta_{(j)} & =\iota_{m(m)}^{\prime}\left[I_{m}-G\right]^{-1}\left[\partial G / \partial \theta_{(j)}\right]\left[I_{m}-G\right]^{-1} \otimes\left(H^{\prime}-I_{n}\right) \\
\partial W_{2} / \partial \theta_{(j)} & =\left[I_{m n}-G \otimes H^{\prime}\right]^{-1}\left[\left(\partial G / \partial \theta_{(j)}\right) \otimes H^{\prime}\right]\left[I_{m n}-G \otimes H^{\prime}\right]^{-1}
\end{array}
$$

Finally, the gradient of the likelihood of friction parameters with respect to the vector of forecast model parameters, $g_{y}\left(h_{x}\right) \equiv \partial L_{y} / \partial h_{x}^{\prime}$, is required for the construction of $M_{\theta, h_{x}^{\prime}}$. Let $h_{x}$ denote the column stack of the first $n_{x}$ rows of the companion matrix of the full forecast model, $H$. 
The ordered elements of this $\left(n_{x} n\right) \times 1$ vector are referenced by $h_{x,\left(k_{i j}\right)}$, where $k_{i j} \equiv(j-1) n_{x}+i$ for $1 \leq i \leq n_{x}$ and $1 \leq j \leq n$. Using this subscripting convention, the required elements of $\partial h_{*} / \partial h_{x}$ are

$$
\begin{aligned}
\partial W_{1} / \partial h_{x,\left(k_{i j}\right)} & =\iota_{m(m)}^{\prime}\left[I_{m}-G\right]^{-1} \otimes\left[\iota_{n(j)} \otimes \iota_{n(i)}^{\prime}\right] . \\
\partial W_{2} / \partial h_{x,\left(k_{i j}\right)} & =\left[I_{m n}-G \otimes H^{\prime}\right]^{-1}\left[G \otimes\left(\iota_{n(j)} \otimes \iota_{n(i)}^{\prime}\right]\left[I_{m n}-G \otimes H^{\prime}\right]^{-1},\right.
\end{aligned}
$$


Table 1

\section{Cointegration Construction of Industry Price Trend ${ }^{a}$}

$$
p_{t}^{*} \propto \theta^{c} p_{t}^{c}+\theta^{i} p_{t}^{i}+\theta^{v} p_{t}^{v}+f(t)
$$

\begin{tabular}{|c|c|c|c|c|c|c|c|c|}
\hline \multirow[b]{2}{*}{ industry } & \multirow[b]{2}{*}{ SIC } & \multicolumn{3}{|c|}{ industry cost share $^{b}$} & \multicolumn{2}{|c|}{$f(t)$} & \multirow[b]{2}{*}{$\mathrm{SEE}^{c}$} & \multirow[b]{2}{*}{$\mathrm{ADF}^{d}$} \\
\hline & & $\theta^{c}$ & $\theta^{i}$ & $\theta^{v}$ & $\rho$ & $t$ & & \\
\hline textiles & 22 & .051 & .339 & .610 & $\begin{array}{l}.359 \\
(5.9)\end{array}$ & $\begin{array}{c}-.0027 \\
(-4.6)\end{array}$ & .036 & $-5.45^{* * *}$ \\
\hline lumber & 24 & .113 & .145 & .741 & & $\begin{array}{l}.0025 \\
(19.4)\end{array}$ & .082 & $-3.47^{* *}$ \\
\hline $\begin{array}{l}\text { rubber \& } \\
\text { plastics }\end{array}$ & 30 & .011 & .449 & .540 & $\begin{array}{c}.278 \\
(10.1)\end{array}$ & $\begin{array}{c}-.0005 \\
(1.6)\end{array}$ & .024 & $-3.85^{* *}$ \\
\hline $\begin{array}{l}\text { primary } \\
\text { metals }\end{array}$ & 33 & .071 & .168 & .761 & $\begin{array}{l}.875 \\
(6.9)\end{array}$ & $\begin{array}{c}-.0019 \\
(-2.6)\end{array}$ & .053 & $-4.59^{* * *}$ \\
\hline $\begin{array}{l}\text { motor } \\
\text { vehicles }\end{array}$ & 371 & .005 & .410 & .585 & & $\begin{array}{l}.0023 \\
(14.2)\end{array}$ & .036 & $-3.10^{*}$ \\
\hline $\begin{array}{l}\text { scientific } \\
\text { instruments }\end{array}$ & 38 & .007 & .341 & .652 & & $\begin{array}{l}.0036 \\
(48.7)\end{array}$ & .046 & $-3.44^{* *}$ \\
\hline
\end{tabular}

${ }^{a}$ Industry-specific log input prices aggregated with industry input share weights into primary commodity, $p^{c}$, intermediate material, $p^{i}$, and value-added, $p^{v}$, input categories. The log of the unit cost of industry value added is estimated by the log of the industry labor compensation rate, $w$, less the log of industry trend productivity, $\rho$.

${ }^{b}$ Constructed from the 1982 US industry input-output accounts, Bureau of Economic Analysis (1991).

${ }^{c}$ Sample span 1957q1-1995q4.

${ }^{d}$ Rejection of the hypothesis that the cointegrating discrepancy, $p_{t}-p_{t}^{*}$, is I $(1)$ at $90 \%(*), 95 \%(* *)$, and $99 \%$ (***) confidence levels, using critical values in MacKinnon (1991). 
Table 2

Industry Price Adjustment Under Geometric Frictions ${ }^{a}$

$$
\Delta p_{t}=-A(1)\left[p_{t-1}-p_{t-1}^{*}\right]+h_{*}^{\prime} z_{t-1}+a_{t}
$$

\begin{tabular}{|c|c|c|c|c|c|c|}
\hline \multirow{3}{*}{$\begin{array}{l}\text { friction } \\
\text { parameters }^{b}\end{array}$} & \multicolumn{6}{|c|}{ manufacturing industries } \\
\hline & $\begin{array}{l}\text { SIC } 22 \\
\text { textiles }\end{array}$ & $\begin{array}{l}\text { SIC } 24 \\
\text { lumber }\end{array}$ & $\begin{array}{c}\text { SIC } 30 \\
\text { rubber \& } \\
\text { plastics }\end{array}$ & $\begin{array}{c}\text { SIC } 33 \\
\text { primary } \\
\text { metals }\end{array}$ & $\begin{array}{c}\text { SIC } 371 \\
\text { motor } \\
\text { vehicles }\end{array}$ & $\begin{array}{c}\text { SIC 38 } \\
\text { scientific } \\
\text { instruments }\end{array}$ \\
\hline & $\mathrm{m}=1$ & $\mathrm{~m}=1$ & $\mathrm{~m}=1$ & $\mathrm{~m}=1$ & $\mathrm{~m}=1$ & $\mathrm{~m}=1$ \\
\hline$A(1)$ & $\begin{array}{c}.09 \\
(2.1)\end{array}$ & $\begin{array}{c}.05 \\
(1.2)\end{array}$ & $\begin{array}{l}.21 \\
(4.4)\end{array}$ & $\begin{array}{c}.13 \\
(3.0)\end{array}$ & $\begin{array}{c}.13 \\
(5.0)\end{array}$ & $\begin{array}{c}.08 \\
(3.9)\end{array}$ \\
\hline $\begin{array}{l}R^{2} \\
C_{E}\end{array}$ & .10 & .13 & .44 & .11 & .62 & .28 \\
\hline$S E E$ & .018 & .030 & .011 & .022 & .010 & .010 \\
\hline$B G(12)^{c}$ & .00 & .03 & .00 & .00 & .00 & .06 \\
\hline friction weights & & & & & & \\
\hline mean lag (qtrs) & 10.2 & 19.4 & 3.8 & 5.9 & 6.6 & 10.9 \\
\hline mean lead (qtrs) & 8.3 & 13.7 & 3.4 & 6.9 & 5.7 & 8.7 \\
\hline $\begin{array}{l}\text { price trend, } \Delta p^{*}, \\
\text { expectations }\end{array}$ & & & & & & \\
\hline$\Delta R^{2}(\%)^{d}$ & $98 \%$ & $7 \%$ & $98 \%$ & $86 \%$ & $10 \%$ & $70 \%$ \\
\hline$L R\left(h_{*} \mid z_{t-1}\right)^{e}$ & .00 & .01 & .00 & .00 & .31 & .01 \\
\hline
\end{tabular}

${ }^{a}$ Sample span 1957q1-1995q4.

${ }^{b} \mathrm{~m}$ denotes the order of the polynomial, $A(L)^{-1}$, that generates friction weights.

${ }^{c}$ Rejection probability of serially independent residuals, Breusch-Godfrey test (12 lags).

${ }^{d}$ Proportion of $R^{2}$ due to forward price trend expectations, $h_{*}^{\prime} z_{t-1} \equiv E_{t}\left\{A(1) \sum_{i=0}^{\infty}(\lambda B)^{i} \Delta p_{t+i}^{*}\right\}$.

${ }^{e}$ Rejection probability of RE overidentifying restrictions on industry expectation coefficient vector, $h_{*}$. 
Table 3

Industry Price Adjustment Under Polynomial Frictions ${ }^{a}$

$$
\Delta p_{t}=-A(1)\left[p_{t-1}-p_{t-1}^{*}\right]+A^{*}(L) \Delta p_{t-1}+h_{*}^{\prime} z_{t-1}+a_{t}
$$

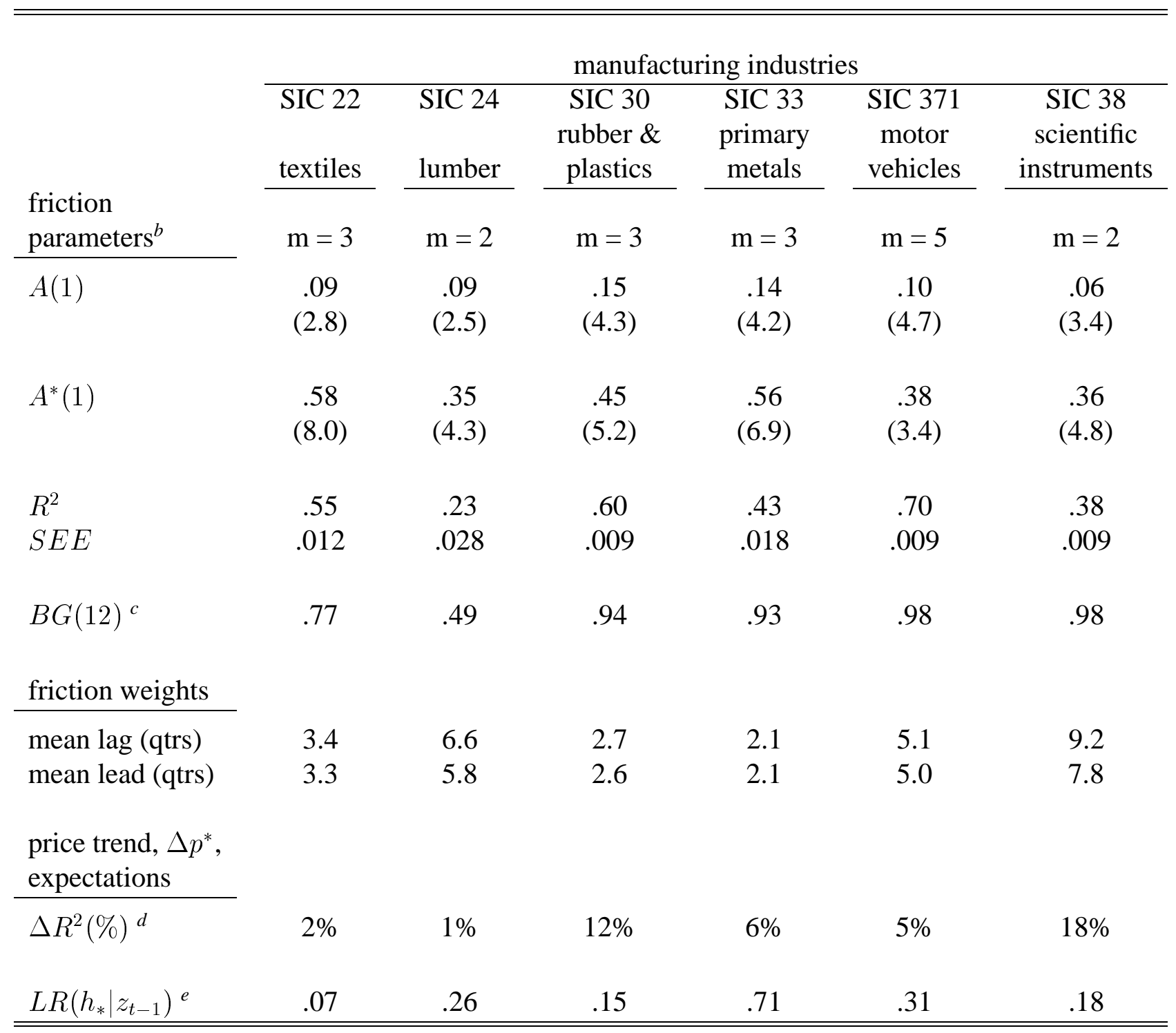

${ }^{a}$ Sample span 1957q1-1995q4.

${ }^{b} \mathrm{~m}$ denotes the order of the polynomial, $A(L)^{-1}$, that generates friction weights.

${ }^{c}$ Rejection probability of serially independent residuals, Breusch-Godfrey test (12 lags).

${ }^{d}$ Proportion of $R^{2}$ due to forward price trend expectations, $h_{*}^{\prime} z_{t-1}$.

${ }^{e}$ Rejection probability of RE overidentifying restrictions on industry expectation coefficient vector, $h_{*}$. 


\section{Table 4}

\section{Industry Price Adjustment with Cyclical Margins ${ }^{a}$}

$$
\Delta p_{t}=-A(1)\left[p_{t-1}-p_{t-1}^{*}\right]+A^{*}(L) \Delta p_{t-1}+h_{*}^{\prime} z_{t-1}+\sum_{k=0}^{1} d_{k} h_{u_{k}}^{\prime} z_{t-1}+a_{t}
$$

\begin{tabular}{|c|c|c|c|c|c|c|}
\hline \multirow{3}{*}{$\begin{array}{l}\text { friction } \\
\text { parameters }^{b}\end{array}$} & \multicolumn{6}{|c|}{ manufacturing industries } \\
\hline & $\begin{array}{l}\text { SIC } 22 \\
\text { textiles }\end{array}$ & $\begin{array}{l}\text { SIC } 24 \\
\text { lumber }\end{array}$ & $\begin{array}{c}\text { SIC } 30 \\
\text { rubber \& } \\
\text { plastics }\end{array}$ & $\begin{array}{c}\text { SIC } 33 \\
\text { primary } \\
\text { metals }\end{array}$ & $\begin{array}{c}\text { SIC } 371 \\
\text { motor } \\
\text { vehicles }\end{array}$ & $\begin{array}{c}\text { SIC } 38 \\
\text { scientific } \\
\text { instruments }\end{array}$ \\
\hline & $\mathrm{m}=3$ & $\mathrm{~m}=2$ & $\mathrm{~m}=3$ & $\mathrm{~m}=3$ & $\mathrm{~m}=5$ & $\mathrm{~m}=2$ \\
\hline \multirow[t]{3}{*}{$A(1)$} & .09 & .08 & .15 & .15 & .11 & .06 \\
\hline & {$[2.9]^{c}$} & {$[2.2]$} & [4.6] & [4.4] & {$[5.7]$} & [3.6] \\
\hline & $(2.9)$ & $(2.2)$ & $(4.2)$ & $(4.3)$ & $(4.5)$ & $(3.2)$ \\
\hline \multirow[t]{3}{*}{$A^{*}(1)$} & .59 & .34 & .44 & .49 & .21 & .36 \\
\hline & {$[8.1]^{c}$} & [4.3] & [6.5] & [5.7] & [1.8] & {$[5.1]$} \\
\hline & $(7.6)$ & $(4.2)$ & $(5.2)$ & $(5.5)$ & $(1.6)$ & $(4.8)$ \\
\hline$R^{2}$ & .57 & .23 & .60 & .45 & .71 & .38 \\
\hline$S E E$ & .012 & .028 & .009 & .018 & .009 & .009 \\
\hline$B G(12)^{d}$ & .88 & .42 & .72 & .95 & .81 & .99 \\
\hline \multicolumn{7}{|l|}{$\begin{array}{l}\text { capacity utilization } \\
\text { expectations }\end{array}$} \\
\hline$L R\left(D(L) \mid z_{t-1}\right)^{e}$ & .07 & .60 & .95 & .04 & .05 & .77 \\
\hline \multirow[t]{3}{*}{$D(1)$} & 0.22 & 0.11 & -0.03 & 0.32 & -0.23 & 0.48 \\
\hline & {$[0.4]^{c}$} & {$[0.1]$} & {$[-0.3]$} & [1.6] & {$[-2.4]$} & [0.6] \\
\hline & $(0.4)$ & $(0.1)$ & $(-0.3)$ & (1.5) & $(-1.9)$ & $(0.6)$ \\
\hline$L R\left(h_{*}, h_{u_{k}} \mid z_{t-1}\right)^{f}$ & .05 & .47 & .06 & .87 & .09 & .09 \\
\hline
\end{tabular}

${ }^{a}$ Sample span 1957q1-1995q4.

${ }^{b}$ m denotes the order of the polynomial, $A(L)^{-1}$, that generates friction weights.

${ }^{c}$-statistics in brackets, [.], are not adjusted for generated regressor bias; see discussion in Appendix.

${ }^{d}$ Rejection probability of serially independent residuals, Breusch-Godfrey test (12 lags).

${ }^{e}$ Rejection probability of no pricing response to expectations of forward utilization rates, $h_{u_{k}}^{\prime} z_{t-1}(k=0,1)$.

${ }^{f}$ Rejection probability of RE overidentifying restrictions on industry expectation coefficient vectors, $h_{*}$ and $h_{u_{k}}$. 
Figure 1: Quarterly Lag and Lead Friction Weights of Producer Pricing Decision Rules ${ }^{a}$
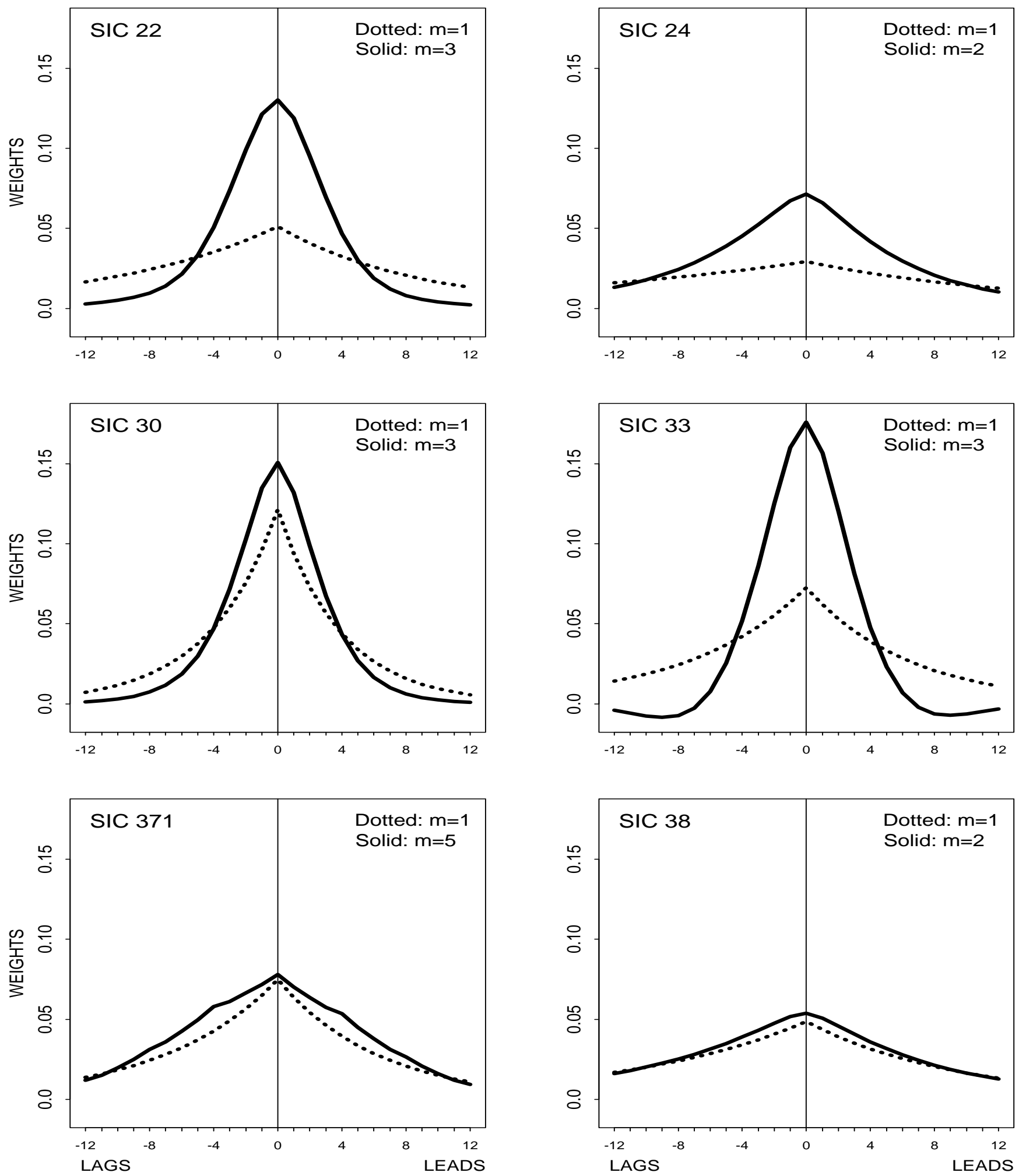

${ }^{a}$ Generated by Euler equations containing $2 m$-order polynomials in lag and lead operators. 